\title{
Correlation of MDR1 gene polymorphism with propofol combined with remifentanil anesthesia in pediatric tonsillectomy
}

\author{
YunLong Zhang ${ }^{1, *}$, Yongpei $\mathrm{Li}^{2, *}$, Hongfa Wang ${ }^{1}$, Fang Cai ${ }^{1}$, Sheliang Shen ${ }^{1}$ and \\ Xiaopan Luo ${ }^{1}$ \\ ${ }^{1}$ Department of Anesthesiology, Zhejiang Provincial People's Hospital, People's Hospital of Hangzhou Medical College, \\ Hangzhou, Zhejiang, China \\ ${ }^{2}$ Hangzhou Women's Hospital, Hangzhou Maternity and Child Health Care Hospital, Hangzhou, Zhejiang, China \\ *The authors contributed equally to the work \\ Correspondence to: Xiaopan Luo, email: 17130802356@163.com \\ Keywords: multidrug resistance gene; single nucleotide polymorphism; propofol; remifentanil; tonsillectomy \\ Received: September 07, 2017 Accepted: October 29, 2017 Epub: December 12, 2017 Published: April 17, 2018 \\ Copyright: Zhang et al. This is an open-access article distributed under the terms of the Creative Commons Attribution License 3.0 \\ (CC BY 3.0), which permits unrestricted use, distribution, and reproduction in any medium, provided the original author and source \\ are credited.
}

\section{ABSTRACT}

The motive of this study was to investigate the interaction between polymorphisms in the MDR1 gene and anesthetic effects following pediatric tonsillectomy. In total, 240 children undergoing tonsillectomy with preoperative propofol-remifentanil anesthesia were selected. Genomic DNA was extracted from the peripheral blood of children after operation, and the MDR1 gene polymorphisms of 2677 G>T/A, 1236 C>T and $3435 \mathrm{C}>\mathrm{T}$ were detected by direct sequencing. We tested mean arterial pressure, diastolic blood pressure, systolic blood pressure, and heart rate at several time-points: TO ( 5 mins after the repose), T1 ( $0 \mathrm{~min}$ after tracheal intubation), T2 (5 mins after the tracheal intubation), T3 (0 $\mathrm{min}$ after the tonsillectomy), T4 (0 $\mathrm{min}$ after removal of the mouth-gag) and T5 (5min after the extubation). The visual analog scale, the face, legs, activity, cry, and consolability pain assessment, and the Ramsay sedation score were recorded after the patients regained consciousness. Adverse reactions were also recorded. The time of induction, respiration recovery, eye-opening, and extubation of children with the CC genotype were found to be shorter compared to the CT+TT genotype of MDR1 1236C>T (all P<.05). The mean arterial pressure, diastolic blood pressure, systolic blood pressure, and heart rate were significantly reduced at T5 in children with the CC genotype (all $P<.05$ ). The visual analog scale at $1,2,4$, and 8 hours post-operation, and the Ramsay sedation score at 5, 10, and $30 \mathrm{~min}$ after the extubation were decreased, while the face, legs, activity, cry, and consolability pain assessment score increased (all $P<0.05$ ). There was no statistically significant difference in the adverse reaction of MDR1 mutations ( $P>0.05)$. It could be concluded that anesthetic effect following pediatric tonsillectomy in patients with the MDR1 $1236 \mathrm{C}>\mathrm{T}$ CC genotype was stronger than in those carrying the CT+TT genotype.

\section{INTRODUCTION}

Tonsillectomy is known to be one of the most common and severely painful surgeries that children undergo 1 [1]. It is conducted inside the oral cavity, and strict anesthesia requirements are needed to eliminate undesirable reflection phenomenon occurring during surgery since it easily leads to throat irritation [2]. In addition, it is conducive to post-operative recovery to maintain stable vital signs in children during surgery since the operation time is short [3]. The tonsils are rich in blood and large amounts of secretions, so more attention should be paid to anesthesia to avoid accidental inhalation during surgery [4]. With recent advancements in anesthetic and surgical techniques, tonsillectomy has become safer than in older times. The 2 main narcotic drugs are propofol and remifentanil [5]. Both 
are ultra-short-acting opioids that have less impact on postoperative recovery and are considered safe [6]. However, studies have shown that nausea, vomiting, muscle stiffness and dose-dependent heart rate (HR) increase and systolic blood pressure decreases after anesthesia, and increased post-operative analgesia is needed because of acute opioid tolerance [7]. MDR1 encodes a 170-kDa transmembrane protein, P-glycoprotein (P-gp). P-gp is an efflux pump for a variety of lipophilic compounds. [8, 9]. MDR1 is expressed in many tissues [10], and many single-nucleotide polymorphisms (SNPs) have been identified in the exons of MDR1. Among these SNPs, 1236C $>$ T, 2677G $>$ T/A, and $3435 \mathrm{C}>\mathrm{T}$ in MDR1 are the main variants that have been investigated [11]. Our study aims to investigate the role of the MDR1 gene polymorphisms $1236 \mathrm{C}>\mathrm{T}, 2677 \mathrm{G}>\mathrm{T} / \mathrm{A}$, and $3435 \mathrm{C}>\mathrm{T}$ in the anesthetic effects of propofol combined with remifentanil. We hope to provide knowledge for better anesthetic effects in pediatric tonsillectomy.

\section{RESULTS}

\section{Allele frequencies of MDR1}

A total of 240 subjects were recruited for this study. According to the sequencing results, the number of wild- type heterozygote patients for MDR1 $2677 \mathrm{G}>\mathrm{T} / \mathrm{A}$ with TG, GA, and TA was 101, 31, and 30 respectively, and the number of mutant homozygote patients with TT, GG and AA was 30, 42, and 6 respectively. The number of patients with MDR1 $1236 \mathrm{C}>\mathrm{T}$ wild homozygote $\mathrm{CC}$, heterozygote $\mathrm{CT}$, and the mutational homozygote TT was 25,118 , and 91, respectively. The number of patients with MDR1 3435 $\mathrm{C}>\mathrm{T}$ wild homozygote $\mathrm{CC}$, heterozygote $\mathrm{CT}$, and mutant homozygote TT was 92, 18, and 40, respectively.

The MDR1 gene distribution for $3435 \mathrm{C}>\mathrm{T}$, $1236 \mathrm{C}>\mathrm{T}$, and $2677 \mathrm{G}>\mathrm{T} / \mathrm{A}$ was consistent with HardyWeinberg equilibrium (all $\mathrm{P}>0.05$ ), which indicated that the gene distribution of MDR1 3435C $>$ T, 1236C $>$ T, and $2677 \mathrm{G}>\mathrm{T} / \mathrm{A}$ achieved genetic equilibrium. It was then recorded and represented in Table 1. The sequencing results for each mutant site are shown in Figure 1.

\section{Effect of MDR1 gene polymorphisms on anesthesia induction and restoration}

No significant differences were found between different genotypes on MDR1 2677G > T/A concerning the time of induction, respiration recovery, eye-opening, and extubation (all $P>0.05$ ). No significant difference was revealed between MDR1 3435C $>$ T CC and CT+TT

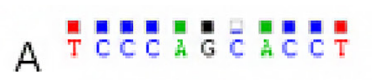

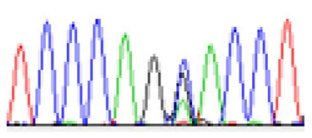

E TTCCCAGAME

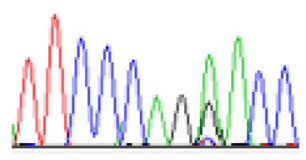

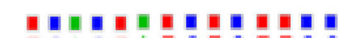

I TCHCTATCTCTTCC

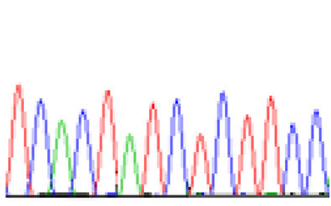

$\mathrm{B}$ T TCEAGCACT
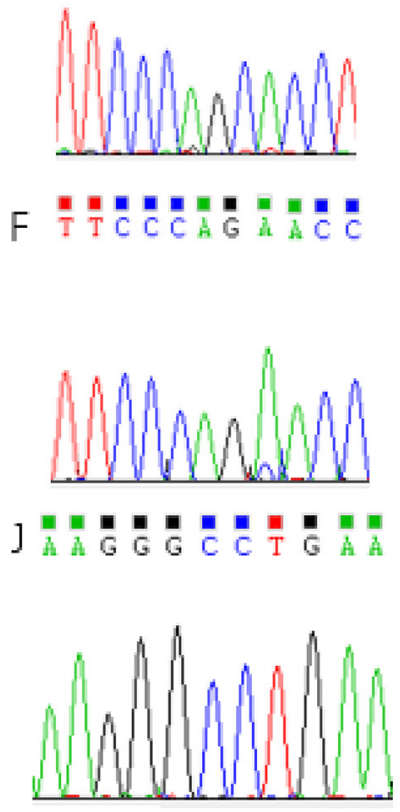
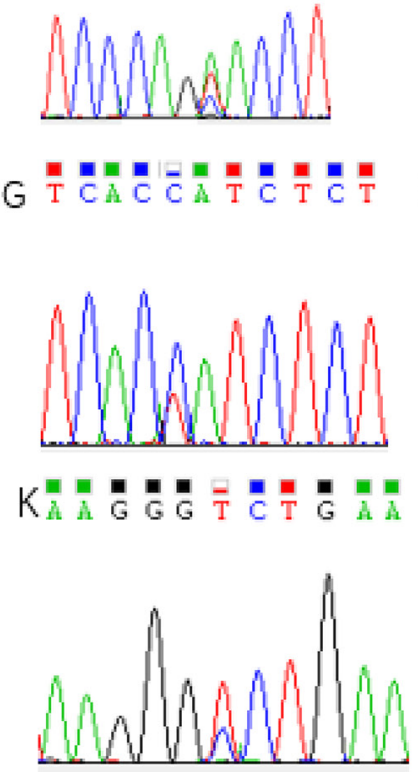
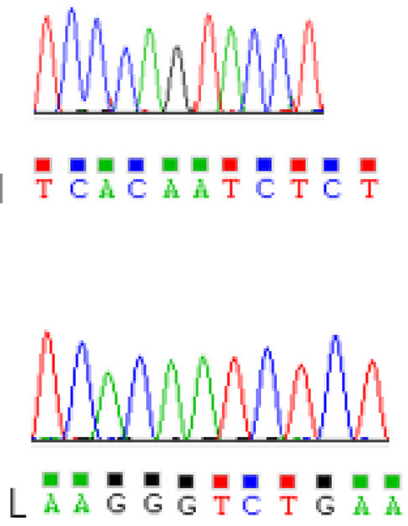

H

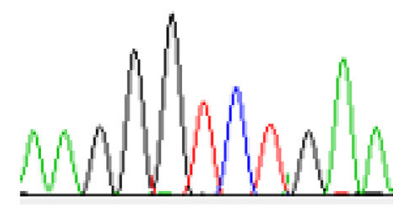

Figure 1: Sequencing results of 2677 G>T/A mutations site in MDR1 gene. (A) 2677 G>T/A GA genotype; (B) 2677 G>T/A GG genotype; (C) 2677 G>T/A TA genotype; (D) 2677 G>T/AAA genotype; (E) 2677 G>T/A TG genotype; (F) 2677 G>T/A TT genotype; (G) 3435C > T CT genotype; (H) 3435C > T CC genotype; (I) 3435C > T TT genotype; (J) 1236C $>$ T CC genotype; (K) 1236C > T CT genotype; (L) $1236 \mathrm{C}>\mathrm{T}$ TT genotype. 
Table 1: Comparison of gene frequencies between each loci of MDR1 gene

\begin{tabular}{|c|c|c|c|c|}
\hline Gene & $\begin{array}{c}\text { Theoretical frequency } \\
(\%)\end{array}$ & Actual frequency $(\%)$ & $\chi^{2}$ & $P$ \\
\hline $2677 \mathrm{G}>\mathrm{T} / \mathrm{A}$ & & & 0.82 & 0.98 \\
\hline TT & $30(12.50)$ & $28(11.67)$ & & \\
\hline TG & $101(42.08)$ & $108(45.00)$ & & \\
\hline GG & $42(17.50)$ & $39(16.25)$ & & \\
\hline GA & $31(12.92)$ & $34(14.17)$ & & \\
\hline TA & $30(12.50)$ & $27(11.25)$ & & \\
\hline AA & $6(2.50)$ & $4(1.67)$ & & \\
\hline $1236 \mathrm{C}>\mathrm{T}$ & & & 0.89 & 0.64 \\
\hline $\mathrm{CC}$ & $25(10.42)$ & $30(12.50)$ & & \\
\hline $\mathrm{CT}$ & $118(49.17)$ & $109(45.42)$ & & \\
\hline TT & $97(40.42)$ & $101(42.08)$ & & \\
\hline $3435 \mathrm{C}>\mathrm{T}$ & & & 0.30 & 0.86 \\
\hline $\mathrm{CC}$ & $92(38.33)$ & $88(36.67)$ & & \\
\hline $\mathrm{CT}$ & $108(45.00)$ & $114(47.50)$ & & \\
\hline TT & $40(16.67)$ & $38(15.83)$ & & \\
\hline
\end{tabular}

genotypes that increased the time of induction, respiration recovery, eye-opening, and extubation (all $P>0.05$ ). Compared to the MDR1 1236C $>$ T CC genotype, children bearing the $\mathrm{CT}+\mathrm{TT}$ genotype exhibited longer times of induction, respiration recovery, eye-opening, and extubation (all $P<0.05$ ), as demonstrated in Table 2.

\section{Effect of MDR1 gene polymorphisms on hemodynamics after extubation}

The MAP, SBP, DBP, and HR of patients with different genotypes at T1, T2, T3, T4, and T5 were found to be lower than those at T0 (all $P<0.05$ ). There was no significant difference revealed between the MDR1 3435C $>$ T CC and CT + TT genotypes i MAP, SBP, DBP, and HR at T0, T1, T2, T3, T4, and T5 (all $P>0.05$ ). This was also applicable for the different genotypes on MDR1 $2677 \mathrm{G}>\mathrm{T} / \mathrm{A}$ (all $P>0.05$ ). Compared to the MDR1 $1236 \mathrm{C}>\mathrm{T} \mathrm{CT}+\mathrm{TT}$ genotype, the children with the CC genotype exhibited significantly reduced MAP, SBP, DBP, and HR at T5 (all $P<0.05$ ) and nonsignificant differences during other time points (all $P>0.05$ ), as demonstrated in Table 3.

\section{Effect of MDR1 gene polymorphisms on VAS assessment}

Compared to VAS at 1 hour post-operation, all the mutations of the genotype of children with postoperative VAS showed a downward trend. There was no significant difference revealed between MDR1 3435C $>\mathrm{T}$ $\mathrm{CC}$ and $\mathrm{CT}+\mathrm{TT}$ genotypes in terms of VAS at each time point (all $P>0.05$ ). Additionally, there was no significant difference observed among the different genotypes on MDR1 2677G $>$ T/A (all $P>0.05$ ). Compared to the MDR1 $1236 \mathrm{C}>\mathrm{T}$ CC genotype, a significantly higher VAS was indicated in children who had the $\mathrm{CT}+\mathrm{TT}$ genotype at $1,2,4$, and 8 hours post-operation (all $P<0.05$ ), as demonstrated in Table 4.

\section{Effect of MDR1 gene polymorphisms on Ramsay sedation score and FLACC assessment}

As shown in Table 6, there was no significant difference between MDR1 3435C $>$ T CC and CT+TT genotypes regarding the Ramsay sedation scores and FLACC scores after extubation for 5, 10, and 30 minutes (all $P>0.05$ ). No significant differences were observed among different genotypes on MDR1 2677G $>$ T/A (all $P>0.05$ ). Compared to the MDR1 $1236 \mathrm{C}>\mathrm{T} \mathrm{CT}+\mathrm{TT}$ genotype, Ramsay scores at the 3 time points were reduced in children with the CC genotype, while FLACC scores were found to be higher (all $P<0.05$ ), as demonstrated in Table 5.

\section{Adverse reaction}

There were 8 cases of adverse reactions to anesthesia that occurred in this study. These included 2 cases of nausea and vomiting found in patients with the 
Table 2: Comparison of anesthesia induction and restoration time between different MDR1 genotypes patients $(\overline{\mathrm{x}} \pm \mathrm{s})$

\begin{tabular}{|c|c|c|c|c|c|}
\hline Genotype & $\mathbf{N}$ & $\begin{array}{c}\text { Time of induction } \\
\text { (min) }\end{array}$ & $\begin{array}{c}\text { Time of respiration } \\
\text { recovery } \\
\text { (min) }\end{array}$ & $\begin{array}{c}\text { Time of eye-opening } \\
\text { (min) }\end{array}$ & $\begin{array}{c}\text { Time of extubation } \\
\text { (min) }\end{array}$ \\
\hline \multicolumn{6}{|c|}{$2677 \mathrm{G}>\mathrm{T} / \mathrm{A}$} \\
\hline TT & 28 & $3.84 \pm 0.32$ & $5.87 \pm 0.61$ & $8.87 \pm 0.62$ & $8.67 \pm 0.65$ \\
\hline TG & 108 & $3.89 \pm 0.46$ & $5.92 \pm 0.62$ & $8.91 \pm 0.72$ & $8.74 \pm 0.68$ \\
\hline GG & 39 & $3.91 \pm 0.54$ & $5.80 \pm 0.71$ & $8.84 \pm 0.65$ & $8.77 \pm 0.74$ \\
\hline GA & 34 & $3.90 \pm 0.61$ & $5.90 \pm 0.59$ & $8.90 \pm 0.67$ & $8.73 \pm 0.67$ \\
\hline TA & 27 & $4.01 \pm 0.58$ & $2.78 \pm 0.54$ & $9.01 \pm 0.79$ & $8.75 \pm 0.81$ \\
\hline AA & 4 & $3.93 \pm 0.57$ & $5.74 \pm 0.63$ & $8.84 \pm 0.81$ & $8.79 \pm 0.78$ \\
\hline \multicolumn{6}{|l|}{$1236 \mathrm{C}>\mathrm{T}$} \\
\hline $\mathrm{CC}$ & 30 & $3.75 \pm 0.45$ & $5.42 \pm 0.46$ & $8.47 \pm 0.68$ & $8.37 \pm 0.71$ \\
\hline $\mathrm{CT}+\mathrm{TT}$ & 210 & $4.12 \pm 0.37 \AA$ & $5.86 \pm 0.48^{\mathbf{A}}$ & $8.92 \pm 0.72^{\Delta}$ & $8.76 \pm 0.75^{\Delta}$ \\
\hline \multicolumn{6}{|l|}{$3435 \mathrm{C}>\mathrm{T}$} \\
\hline $\mathrm{CC}$ & 88 & $3.98 \pm 0.48$ & $5.96 \pm 0.74$ & $8.83 \pm 0.81$ & $8.78 \pm 0.71$ \\
\hline $\mathrm{CT}+\mathrm{TT}$ & 152 & $3.94 \pm 0.44$ & $5.93 \pm 0.68$ & $8.86 \pm 0.84$ & $8.72 \pm 0.81$ \\
\hline
\end{tabular}

$\mathrm{N}=$ number

$\Delta P<0.05$ compared with the CC genotype.

$2677 \mathrm{G}>\mathrm{T} / \mathrm{A}$ CC genotype, 3 cases in patients with the $1236 \mathrm{C}>\mathrm{TCT}+\mathrm{TT}$ genotype, and 2 cases in patients with the $3435 \mathrm{C}>\mathrm{TCC}$ genotype; 1 case of agitation in the recovery period was found with the $1236 \mathrm{C}>\mathrm{T} \mathrm{CC}$ genotype. The comparisons of adverse reaction rate among different genotypes on MDR1 mutations were found to be nonsignificant (all $P>0.05$ ).

\section{DISCUSSION}

Tonsil hypertrophy is a common pediatric disease. It may cause airway obstruction, which can affect sleep quality in children and promote the accumulation of $\mathrm{CO} 2$ in the lungs, possibly resulting in mental development abnormalities. Tonsillectomy is a common surgical procedure for tonsil hypertrophy $[14,15]$. Tonsillectomy is performed inside the oral cavity; strict anesthesia requirements are needed since it can easily lead to throat irritation, and children often have a low degree of coordination during the surgery. To prevent adverse events during surgery, safe and effective anesthesia is of great significance not only for the operation but also for postoperative recovery $[16,17]$.

Recently, it was showndrug anesthetic or analgesic effect varies because of gene polymorphism $[18,19]$. MDR1 is an important transporter that can constrain the accumulation of chemotherapeutic drugs [20]. The role of the $1236 \mathrm{C}>\mathrm{T}, 2677 \mathrm{G}>\mathrm{T} / \mathrm{A}$, and $3435 \mathrm{C}>\mathrm{T}$ MDR 1 gene polymorphisms on the anesthetic effects of the drug propofol combined with remifentanil was investigated in our study. The results we obtained revealed that the $1236 \mathrm{C}>\mathrm{T}$ SNP contributed to individual variation in anesthetic effects following pediatric tonsillectomy. We determined that the patients with the MDR 1 1236C $>$ T CC genotype displayed superior anesthetic effects compared to patients with the CT+TT genotype. Takashina et al [21] study showed that MDR1 gene $1236 \mathrm{C}>\mathrm{T}$ polymorphism can change remifentanil analgesic effect during the treatment of cancer pain, and found that patients of CC genotype have better results, which is consistent with our study. Analysis of the reasons may be due to patients of TT genotype need the largest dose of remifentanil and propofol, for they may accumulated in liver cells due to the decreased transport function of P-gp in patients of TT genotype, remifentanil and propofol are metabolized in the liver, resulting in increased dose of the drug needs.

Our study demonstrated that children with the CC genotype exhibited shorter times of induction, respiration recovery, eye-opening, and extubation compared to the MDR1 1236C $>$ T CT + TT genotype. MDR1 is something that can be found in a variety of tissues including gastrointestinal and nasal respiratory mucosa, liver, kidneys, placenta, and the adrenal cortex [22]. It is known that Propofol and remifentanil have been extensively 
Table 3: Comparison of hemodynamics parameters of different mdr1 genotype patients $(\overline{\mathrm{x}} \pm \mathrm{s})$

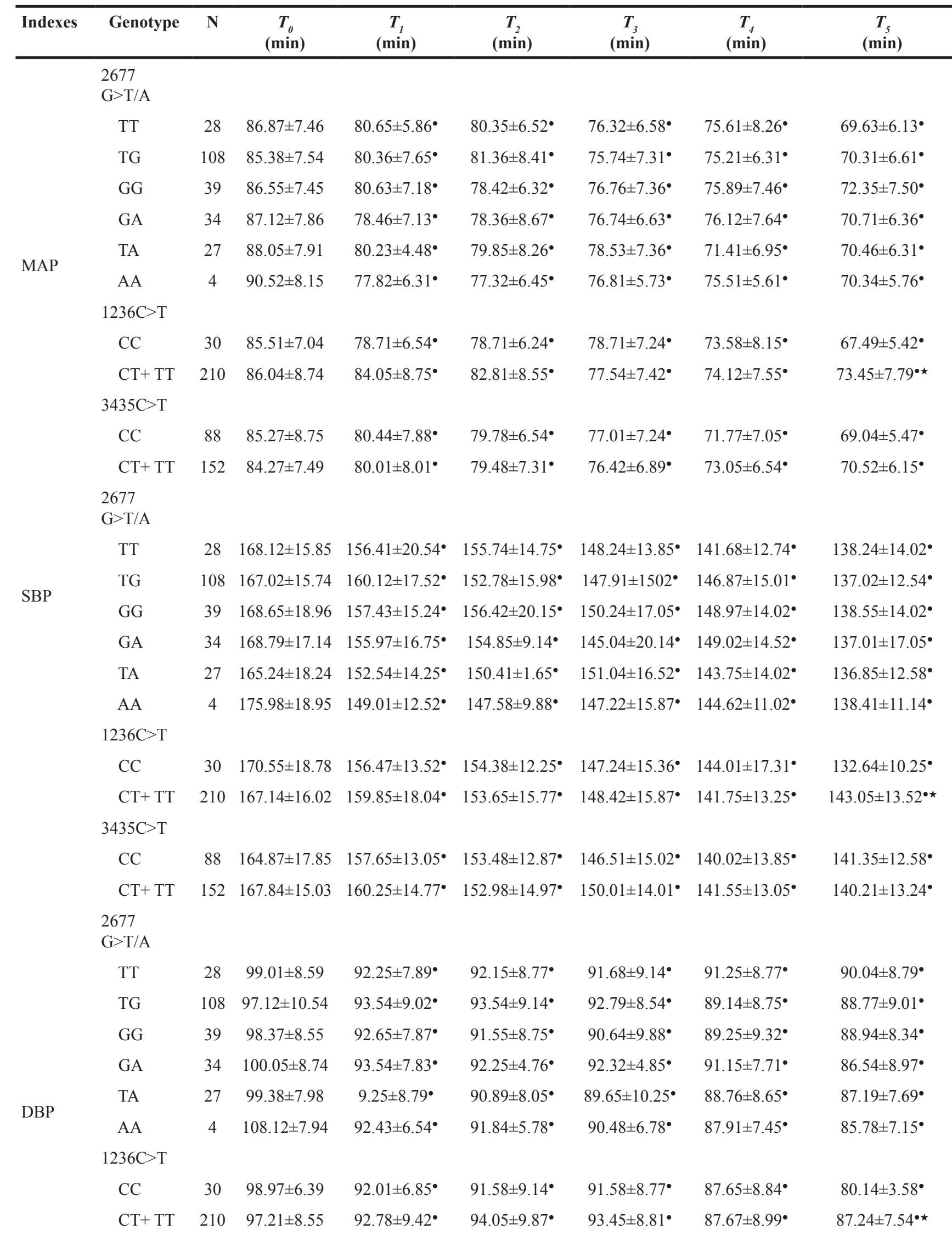

(Continued) 


\begin{tabular}{|c|c|c|c|c|c|c|c|c|}
\hline Indexes & Genotype & $\mathbf{N}$ & $\begin{array}{c}T_{0} \\
(\min )\end{array}$ & $\begin{array}{c}T_{1} \\
(\min )\end{array}$ & $\begin{array}{c}T_{2} \\
(\min )\end{array}$ & $\begin{array}{c}T_{3} \\
(\min )\end{array}$ & $\begin{array}{c}T_{4} \\
(\mathrm{~min})\end{array}$ & $\begin{array}{c}T_{5} \\
(\min )\end{array}$ \\
\hline \multirow{16}{*}{ HR } & $3435 \mathrm{C}>\mathrm{T}$ & & & & & & & \\
\hline & $\mathrm{CC}$ & 88 & $98.37 \pm 8.75$ & $94.15 \pm 10.25^{\bullet}$ & $93.77 \pm 8.68^{\bullet}$ & $93.25 \pm 7.76^{\bullet}$ & $90.28 \pm 7.58^{\bullet}$ & $88.7 \pm 9.24^{\bullet}$ \\
\hline & $\mathrm{CT}+\mathrm{TT}$ & 152 & $96.24 \pm 8.05$ & $92.97 \pm 8.79^{\bullet}$ & $92.75 \pm 9.43^{\bullet}$ & $92.35 \pm 9.71^{\bullet}$ & $90.14 \pm 8.75^{\bullet}$ & $86.65 \pm 8.21^{\bullet}$ \\
\hline & $\begin{array}{l}2677 \\
G>T / A\end{array}$ & & & & & & & \\
\hline & TT & 28 & $94.73 \pm 9.21$ & $81.24 \pm 9.75^{\bullet}$ & $82.05 \pm 7.05^{\bullet}$ & $76.02 \pm 7.64^{\bullet}$ & $73.54 \pm 7.15^{\bullet}$ & $75.78 \pm 6.02^{\bullet}$ \\
\hline & TG & 108 & $96.54 \pm 9.41$ & $79.65 \pm 8.01^{\bullet}$ & $79.68 \pm 7.54^{\bullet}$ & $78.54 \pm 6.75^{\bullet}$ & $73.24 \pm 6.85^{\bullet}$ & $78.35 \pm 6.24^{\bullet}$ \\
\hline & GG & 39 & $96.8 \pm 10.24$ & $79.62 \pm 7.58^{\bullet}$ & $77.68 \pm 8.79^{\bullet}$ & $76.65 \pm 7.43^{\bullet}$ & $72.43 \pm 7.15^{\bullet}$ & $76.02 \pm 7.21^{\bullet}$ \\
\hline & GA & 34 & $96.89 \pm 10.24$ & $81.58 \pm 7.45^{\bullet}$ & $82.54 \pm 6.78^{\bullet}$ & $78.05 \pm 6.84^{\bullet}$ & $73.85 \pm 7.25^{\bullet}$ & $77.89 \pm 7.24^{\bullet}$ \\
\hline & TA & 27 & $97.78 \pm 9.41$ & $82.03 \pm 7.54^{\bullet}$ & $80.94 \pm 7.78^{\bullet}$ & $77.79 \pm 8.02^{\bullet}$ & $72.68 \pm 7.15^{\bullet}$ & $77.79 \pm 7.21^{\bullet}$ \\
\hline & $\mathrm{AA}$ & 4 & $97.85 \pm 6.68$ & $83.56 \pm 8.14^{\bullet}$ & $75.01 \pm 10.25^{\bullet}$ & $75.43 \pm 8.01^{\bullet}$ & $69.64 \pm 6.38^{\bullet}$ & $75.81 \pm 8.01^{\bullet}$ \\
\hline & $1236 \mathrm{C}>\mathrm{T}$ & & & & & & & \\
\hline & $\mathrm{CC}$ & 30 & $95.02 \pm 8.02$ & $85.24 \pm 7.31^{\bullet}$ & $84.68 \pm 9.78^{\bullet}$ & $82.03 \pm 8.78^{\bullet}$ & $74.25 \pm 7.25^{\bullet}$ & $67.54 \pm 7.02^{\bullet}$ \\
\hline & $\mathrm{CT}+\mathrm{TT}$ & 210 & $95.89 \pm 9.77$ & $86.45 \pm 8.24^{\bullet}$ & $83.65 \pm 8.41^{\bullet}$ & $82.05 \pm 7.85^{\bullet}$ & $75.1 \pm 7.05^{\bullet}$ & $74.51 \pm 7.51^{\bullet \star}$ \\
\hline & $3435 \mathrm{C}>\mathrm{T}$ & & & & & & & \\
\hline & $\mathrm{CC}$ & 88 & $96.54 \pm 9.78$ & $81.64 \pm 7.58^{\bullet}$ & $79.65 \pm 8.15^{\bullet}$ & $76.24 \pm 7.54^{\bullet}$ & $73.02 \pm 8.54^{\bullet}$ & $71.25 \pm 602^{\bullet}$ \\
\hline & $\mathrm{CT}+\mathrm{TT}$ & 152 & $96.38 \pm 8.91$ & $86.65 \pm 8.79^{\bullet}$ & $78.14 \pm 7.98^{\bullet}$ & $75.55 \pm 6.85^{\bullet}$ & $73.15 \pm 6.48^{\bullet}$ & $72.36 \pm 6.85^{\bullet}$ \\
\hline
\end{tabular}

$\mathrm{N}=$ number, $\mathrm{MAP}=$ mean arterial pressure, $\mathrm{SBP}=$ systolic blood pressure, $\mathrm{DBP}=$ diastolic blood pressure, $\mathrm{HR}=$ heart rate.

$-P<0.05$ compared with T0.

${ }^{\star} P<0.05$ compared with $\mathrm{CC}$ genotype.

applied for anesthesia, analgesia, and procedural sedation [23-25]. The hemodynamic stability during anesthesia is often measured using MAP, SBP, DBP, and HR [26]. VAS, Ramsay, and FLACC scores are used to assess the pain scales after the emergence from anesthesia [27, 28]. Propofol-remifentanil anesthesia has a remarkable effect during tonsillectomy for its stable hemodynamics, short post-operative recovery time and high safety [5]. The study has also revealed that children with the CC genotype displayed significantly reduced MAP, SBP, DBP, and $\mathrm{HR}$ at T5 compared to the MDR1 $1236 \mathrm{C}>\mathrm{T}$ CT $+\mathrm{TT}$ genotype. Significantly higher VAS were indicated in children with the $\mathrm{CT}+\mathrm{TT}$ genotype at post-operative 1 , 2, 4, and 8 hours compared to the MDR1 1236C > T CC genotype. Ramsay scores were reduced in children after extubation for 5, 10, and 30 minutes with the CC genotype compared to the MDR1 $1236 \mathrm{C}>\mathrm{T}$ CT+TT genotype, while FLACC scores were found to be higher with the CC genotype.

We sought the cause and found that a critical impact on the therapeutic efficacy and the pharmacokinetics of drugs are varied in alterations in the expression and the activity of MDR1-encoded P-gp. Because of this, P-gp levels can influence the entrance of drugs into the cells. [29] Evidence suggests that elevated levels and enhanced activity of P-gp are conferred more by the CC genotype, while individuals with the TT genotype seem to have decreased P-gp activity. [30] Studies have found that genetic causes of MDR1 for the anesthetic effects are varied. MDR1 genetic variants rs12720464 and rs1055302 account for the individual variation of time of action in patients undergoing anesthesia with a single dose of rocuronium. Another study indicates that children who possess GG and GA genotypes of MDR1 rs9282564 present higher risks of opioid-related respiratory depression that lead to prolonged hospitalization. The minor allele $(\mathrm{G})$ elevates the odds of a prolonged stay due to post-operative respiratory depression [31]. The experiment by Sia et al connects MDR1 $1236 \mathrm{C}>\mathrm{T}$, $2677 \mathrm{G}>\mathrm{T} / \mathrm{A}$, and $3435 \mathrm{C}>\mathrm{T}$ to chronic pain in women receiving spinal anesthesia with intrathecal morphine for elective cesarean section. They revealed no significant difference in the total consumption of morphine, side effects, and pain scores among different genotypes. Women with the $3435 \mathrm{C}>\mathrm{T}$ allele demonstrated a higher risk of suffering persistent post-operative pain [32]. Farhat et al's [33] experiment indicated that managing nausea and vomiting during intravenous administration of ondansetron are all related to the MDR1 $2677 \mathrm{G}>\mathrm{T} / \mathrm{A}$ TT genotype, which is similar to our findings. Our study confirmed that there is no significant association between the SNPs $2677 \mathrm{G}>\mathrm{T} / \mathrm{A}$ and $3435 \mathrm{C}>\mathrm{T}$ that change anesthesia 
Table 4: Comparison of VAS scores between different MDR1 genotypes patients $(\overline{\mathrm{x}} \pm \mathrm{s})$

\begin{tabular}{|c|c|c|c|c|c|}
\hline Geneotye & $\mathbf{N}$ & $1 \mathrm{~h}$ & $2 \mathrm{~h}$ & $4 h$ & $8 h$ \\
\hline \multicolumn{6}{|c|}{$2677 \mathrm{G}>\mathrm{T} / \mathrm{A}$} \\
\hline TT & 28 & $4.85 \pm 1.21$ & $3.75 \pm 1.42^{\Delta}$ & $2.21 \pm 0.78^{\Delta}$ & $2.04 \pm 0.45^{\Delta}$ \\
\hline TG & 108 & $4.77 \pm 0.98$ & $3.42 \pm 1.05^{\Delta}$ & $2.54 \pm 0.92^{\Delta}$ & $2.08 \pm 0.43^{\Delta}$ \\
\hline GG & 39 & $4.57 \pm 1.52$ & $3.73 \pm 1.05^{\Delta}$ & $2.34 \pm 0.94^{\Delta}$ & $2.14 \pm 0.51^{\Delta}$ \\
\hline GA & 34 & $4.73 \pm 1.25$ & $3.32 \pm 1.21^{\Delta}$ & $3.02 \pm 0.74^{\Delta}$ & $2.22 \pm 0.61^{\Delta}$ \\
\hline TA & 27 & $4.76 \pm 1.32$ & $3.85 \pm 1.42^{\Delta}$ & $2.54 \pm 0.73^{\Delta}$ & $2.15 \pm 0.71^{\Delta}$ \\
\hline AA & 4 & $4.61 \pm 1.35$ & $2.84 \pm 1.02^{\Delta}$ & $2.84 \pm 0.56^{\Delta}$ & $2.56 \pm 0.64^{\Delta}$ \\
\hline \multicolumn{6}{|l|}{$1236 \mathrm{C}>\mathrm{T}$} \\
\hline $\mathrm{CC}$ & 30 & $3.94 \pm 0.97$ & $3.21 \pm 0.65^{\Delta}$ & $2.01 \pm 0.42^{\Delta}$ & $1.69 \pm 0.42^{\Delta}$ \\
\hline $\mathrm{CT}+\mathrm{TT}$ & 210 & $4.67 \pm 1.05^{\wedge}$ & $3.98 \pm 0.61^{\wedge} \Delta$ & $2.65 \pm 0.47^{\Delta} \Delta$ & $2.34 \pm 0.74^{\Delta} \Delta$ \\
\hline \multicolumn{6}{|l|}{$3435 \mathrm{C}>\mathrm{T}$} \\
\hline $\mathrm{CC}$ & 88 & $4.56 \pm 1.35$ & $3.75 \pm 1.24^{\Delta}$ & $2.54 \pm 1.20^{\Delta}$ & $1.98 \pm 0.84^{\Delta}$ \\
\hline $\mathrm{CT}+\mathrm{TT}$ & 152 & $4.61 \pm 1.24$ & $3.84 \pm 1.36^{\Delta}$ & $2.34 \pm 1.04^{\Delta}$ & $2.02 \pm 0.87^{\Delta}$ \\
\hline
\end{tabular}

注: $\mathrm{N}=$ number, VAS=Visual Analogue Scale.

${ }^{\Delta} P<0.05$ compared with 1 h.

$\Delta P<0.05$ compared with CC genotype.

Table 5: Comparison of Ramsay sedation score and FLACC score between different MDR1 genotypes patients $(\overline{\mathrm{x}} \pm \mathrm{s})$

\begin{tabular}{|c|c|c|c|c|c|c|c|}
\hline \multirow[t]{2}{*}{ Genotype } & \multirow[t]{2}{*}{$\mathbf{N}$} & \multirow{2}{*}{$\frac{\text { Ramsay }}{5 \mathrm{~min}}$} & \multicolumn{5}{|c|}{ FLACC } \\
\hline & & & $10 \mathrm{~min}$ & 30min & $5 \mathrm{~min}$ & $10 \mathrm{~min}$ & 30min \\
\hline \multicolumn{8}{|c|}{$2677 \mathrm{G}>\mathrm{T} / \mathrm{A}$} \\
\hline $\mathrm{TT}$ & 28 & $0.98 \pm 0.31$ & $1.55 \pm 0.61$ & $1.84 \pm 0.50$ & $4.15 \pm 0.71$ & $4.11 \pm 1.20$ & $3.01 \pm 0.75$ \\
\hline TG & 108 & $0.99 \pm 0.32$ & $1.62 \pm 0.57$ & $1.75 \pm 0.52$ & $4.29 \pm 0.73$ & $3.74 \pm 1.04$ & $3.19 \pm 0.58$ \\
\hline GG & 39 & $0.96 \pm 0.34$ & $1.78 \pm 0.52$ & $1.69 \pm 0.54$ & $4.33 \pm 0.64$ & $3.59 \pm 1.21$ & $3.12 \pm 0.58$ \\
\hline GA & 34 & $0.98 \pm 0.35$ & $1.79 \pm 0.65$ & $1.66 \pm 0.54$ & $4.26 \pm 0.68$ & $3.54 \pm 1.17$ & $3.24 \pm 0.45$ \\
\hline TA & 27 & $1.01 \pm 0.54$ & $1.62 \pm 0.54$ & $1.65 \pm 0.47$ & $4.43 \pm 0.72$ & $3.75 \pm 1.09$ & $3.25 \pm 0.56$ \\
\hline $\mathrm{AA}$ & 4 & $0.78 \pm 0.52$ & $2.04 \pm 0.86$ & $1.26 \pm 0.51$ & $4.76 \pm 1.01$ & $4.05 \pm 0.89$ & $3.54 \pm 0.61$ \\
\hline \multicolumn{8}{|l|}{$1236 \mathrm{C}>\mathrm{T}$} \\
\hline $\mathrm{CC}$ & 30 & $0.57 \pm 0.54$ & $1.13 \pm 0.34$ & $1.24 \pm 0.41$ & $4.48 \pm 1.06$ & $4.49 \pm 1.15$ & $4.15 \pm 0.86$ \\
\hline $\mathrm{CT}+\mathrm{TT}$ & 210 & $1.13 \pm 0.41$ • & $1.55 \pm 0.51 \bullet$ & $1.65 \pm 0.57$ & $3.91 \pm 0.94 "$ & $3.85 \pm 0.91$ • & $3.15 \pm 0.65^{\bullet}$ \\
\hline \multicolumn{8}{|l|}{$3435 \mathrm{C}>\mathrm{T}$} \\
\hline $\mathrm{CC}$ & 88 & $1.04 \pm 0.35$ & $1.59 \pm 0.50$ & $1.75 \pm 0.58$ & $3.67 \pm 1.21$ & $3.68 \pm 1.20$ & $3.21 \pm 0.61$ \\
\hline $\mathrm{CT}+\mathrm{TT}$ & 152 & $1.03 \pm 0.36$ & $1.57 \pm 0.54$ & $1.73 \pm 0.61$ & $3.63 \pm 1.15$ & $3.64 \pm 1.09$ & $3.26 \pm 0.65$ \\
\hline
\end{tabular}

$-P<0.05$ compared with CC genotype. 
Table 6: Amplified primers of MDR mutations sites

\begin{tabular}{ll}
\hline Primer & $\mathbf{5}{ }^{\prime} \rightarrow \mathbf{3}^{\prime}$ \\
\hline $2677 \mathrm{G}>\mathrm{T} / \mathrm{A}$ & F:5'-TGCAGGCTATAGGTTCCAGG-3' \\
& R:5' -TTTAGTTTGACTCACCTTCCCG-3' \\
& F:5'-TCTTTGTCACTTTATCCAGC-3' \\
& R:5'-TCTCACCATCCCCTCTGT-3' \\
$3435 \mathrm{C}>\mathrm{T}$ & F:5'-GCTGCTTGATGGCAAAGAAA-3' \\
& R:5' -ATTAGGCAGTGACTCGATGATGA-3' \\
\hline
\end{tabular}

$\mathrm{F}=$ forward, $\mathrm{R}=$ reverse.

induction, emergence from anesthesia, hemodynamic changes, pain assessment, or adverse reactions.

However, the statistical analysis may have some limitations due to the small sample size, and it is necessary to enlarge the sample size in further study, such as increasing the number of genotypes samples. In addition, due to the limited number of samples, this study did not distinguish children from different ethnic groups, which is also need to analysis in the next study.

In conclusion, it can be said that our study gives evidence that the MDR1 SNP $1236 \mathrm{C}>\mathrm{T}$ is partly the reason for single differences in the anesthetic effects that follow pediatric tonsillectomy. Additionally, children who possess the MDR1 1236C > T CC genotype were shown to have superior anesthetic effects in terms of anesthetic induction and restoration, hemodynamic changes, pain and sedation assessment compared to children who possess the CT+TT genotype.

Since the time and budget were limited, it was impossible to conduct the experiments in a larger population. In addition, we believe that further analysis of interactions between varieties of gene polymorphisms in populations from different regions and of different races in China would be significant and warrants in further study.

\section{MATERIALS AND METHODS}

\section{Subject and grouping}

Two hundred and forty children, including 142 males and 98 females, received tonsillectomy with general propofol-remifentanil anesthesia at Zhejiang provincial people's hospital from August 2012 to September 2016. All the children recruited for this study were between the ages of 3 and 12 years with a mean age of $7.05 \pm 2.30$ years, and they weighed between 13 and $45 \mathrm{~kg}$. The mean time to complete the operation was $44.85 \pm 8.15$ minutes. The involvement criteria for eligible patients were as follows: people who underwent post-operative analgesia voluntarily and people who had no allergy history to any kind of anesthetic drugs or no operation contraindication. The non-involvement criteria for non-eligible patients were as follows: heart block or cardiac abnormalities, liver or renal dysfunction, drug abuse history, and allergy to any kind of drug used in this study. This experiment was approved by the Ethics Committee of Zhejiang provincial people's hospital. Informed consent for anesthesia was obtained from the parents or legal guardians.

\section{Methods}

All children were anesthetized with intravenous 0.1 $\mathrm{mg} / \mathrm{kg}$ dexamethasone and $0.01 \mathrm{mg} / \mathrm{kg}$ scopolamine. Target-controlled infusion pump induction of anesthesia was activated. Remifentanil (Yichang people Fook Pharmaceutical Co., Ltd., batch number: 20140197) and propofol (Sichuan Guorui Pharmaceutical Limited liability company, batch number: 20150824) initial doses were set at $2.5 \mu \mathrm{g} / \mathrm{L}$ and $2.5 \mathrm{mg} / \mathrm{L}$, respectively, after imputing parameters such as the child's weight, age and others. Intravenous infusion of $0.1 \mathrm{mg} / \mathrm{kg}$ vecuronium by endotracheal intubation then followed. The bispectral index was maintained at 45-55 during surgery. The propofol concentration was adjusted at any time to maintain the mean arterial pressure (MAP) at $60 \sim 90 \mathrm{mmHg}$ and the heart rate at $80 \sim 120$ beats / min. The remifentanil concentration was adjusted to maintain the stability of anesthesia, and vecuronium was used as appropriate. Remifentanil infusion was ceased at the end of the surgery and propofol infusion stopped 5 minutes after the surgery. The ventilator was cleared when children began to breathe, cough, and swallow normally. The patient was transferred to the observation room at 5 minutes after the oxygen supply stopped, and the percutaneous oxygen saturation (SPO2) stabilized at approximately $95 \%$.

Hemodynamics after anesthesia: The times taken for the following activities were recorded: time of anesthesia induction, eye-opening, respiration recovery, and extubation. Mean arterial pressure (MAP), diastolic blood pressure (DBP), systolic blood pressure (SBP), and HR of different genotypes were recorded and 
compared at 5 minutes after repose (T0), 0 minutes after tracheal intubation (T1), 5 minutes after tracheal intubation (T2), 0 minutes after tonsillectomy (T3), 0 minutes after removal of mouth-gag (T4) and 5 minutes after extubation (T5).

Analgesia and adverse reaction observation: At 1, 2,4 , and 8 hours post-operation, the visual analog scale (VAS) was recorded [12]. The Ramsay sedation score was assessed at 5, 15, and 30 minutes after extubation: 1 point for anxiousness or restlessness; 2 points for cooperativeness and tranquility; 3 points for responding to commands with unclear murmurs; 4 points for drowsiness and brisk response to calling; 5 points for drowsiness and sluggish response to calling; and 6 points for deep sleep or anesthesia [13]. The Face, Legs, Activity, Cry, and Consolability (FLACC) pain assessment was assessed at 5, 15, and 30 minutes after extubation: 0 points for content and relaxed; 1 to 3 for slight pain; 4 to 6 for medium pain; and 7 to 10 for severe pain and uncomfortable. We also observed the adverse reaction rate post-operation followed by consciousness.

Peripheral blood sampling and DNA extraction: Fasting venous blood ( $3 \mathrm{~mL})$ was sampled and placed into a sodium citrate anticoagulation tube labeled with the subject number and name. Using a DNA extraction kit (Article No., 52304; Qiagen Company, Hilden, Germany), the blood was centrifuged at $3000 \mathrm{rpm} /$ min for 10 minutes to extract whole blood DNA from the peripheral blood. Fasting venous blood $(3 \mathrm{~mL})$ was sampled and placed into the sodium citrate anticoagulation tube labeled with the subject number and name. Using a DNA extraction kit (Article No., 52304; Qiagen Company, Hilden, Germany), the blood was centrifuged at $3000 \mathrm{rpm} / \mathrm{min}$ for 10 minutes to extract whole blood DNA from the peripheral blood and stored at $-80^{\circ}$. We detected $2677 \mathrm{G}>\mathrm{T} / \mathrm{A}, 1236$ $\mathrm{C}>\mathrm{T}$ and $3435 \mathrm{C}>\mathrm{T}$ mutations in the MDR1 gene based on extracted genomic DNA. The sequencing primers are shown in Table 6 . The sequencing results were opened and analyzed using Chromas (version 2.41) software.

\section{Statistical analysis}

Statistical analysis was performed using SPSS 19.0 (SPSS Inc., Chicago, IL). Measurement data were expressed as the mean \pm standard deviation $( \pm s)$, and comparisons between two groups using were tested using the $t$ test. Counting data was expressed as [n (\%)], and the $\chi 2$ test was used for statistical analysis with a significance level of 0.05 . $\mathrm{P}<0.05$ was statistically significant.

\section{CONFLICTS OF INTEREST}

There is no conflicts of interest in this study.

\section{FUNDING}

The study was supported by the fund of Health Bureau of Zhejiang province (2017209464); the program of Science and Technology Office of Zhejiang province (No. 2014C37056).

\section{REFERENCES}

1. Gorman D, Ogston S, Hussain SS. Improvement in symptoms of obstructive sleep apnoea in children following tonsillectomy versus tonsillotomy: a systematic review and meta-analysis. Clin Otolaryngol. 2017; 42:275-282.

2. Ama EH, Yassin HM. Effect of intranasal dexmedetomidine on emergence agitation after sevoflurane anesthesia in children undergoing tonsillectomy and/or adenoidectomy. Saudi J Anaesth. 2017; 11:137-143.

3. Shay S, Shapiro NL, Bhattacharyya N. Revisit rates and diagnoses following pediatric tonsillectomy in a large multistate population. Laryngoscope. 2015; 125:457-461.

4. Koyuncu O, Turhanoglu S, Tuzcu K, Karcioglu M, Davarcı I, Akbay E, Cevik C, Ozer C, Sessler DI, Turan A. Effect of carboxyhemoglobin on postoperative complications and pain in pediatric tonsillectomy patients. Paediatr Anaesth. 2015; 25:247-252.

5. Hou Y, Anesthesiology DO. The analgesic effect of combined application of Propofol and Remifentanil in pediatric tonsillectomy. Clin J Med Off. 2014; 42:370-372.

6. Alexander R, Olufolabi AJ, Booth J, El-Moalem HE, Glass PS. Dosing study of remifentanil and propofol for tracheal intubation without the use of muscle relaxants. Anaesthesia. 2015; 54:1037-1040.

7. Alexander R, Booth J, Olufolabi AJ, El-Moalem HE, Glass PS. Comparison of remifentanil with alfentanil or suxamethonium following propofol anaesthesia for tracheal intubation. Anaesthesia. 2015; 54:1032-1036.

8. Ray A, Tennakoon L, Keller J, Sarginson JE, Ryan HS, Murphy GM, Lazzeroni LC, Trivedi MH, Kocsis JH, DeBattista C, Schatzberg AF. ABCB1 (MDR1) predicts remission on $\mathrm{P}$-gp substrates in chronic depression. Pharmacogenomics J. 2015; 15:332-339.

9. Schaich M, Soucek S, Thiede C, Ehninger G, Illmer T; SHG AML96 Study Group. MDR1 and MRP1 gene expression are independent predictors for treatment outcome in adult acute myeloid leukaemia. Br J Haematol. 2015; 128:324-332.

10. Yun M, Lee D, Park MN, Kim EO, Sohn EJ, Kwon BM. Cinnamaldehyde derivative (CB-PIC) sensitizes chemoresistant cancer cells to drug-induced apoptosis via suppression of MDR1 and its upstream STAT3 and AKT signalling. Cell Physiol Biochem. 2015; 35:1821-1830.

11. Wolking S, Schaeffeler E, Lerche H, Schwab M, Nies AT. Impact of genetic polymorphisms of ABCB1 (MDR1, P-Glycoprotein) on drug disposition and potential clinical 
implications: update of the literature. Clin Pharmacokinet. 2015; 54:709-735.

12. Myrvik MP, Drendel AL, Brandow AM, Yan K, Hoffmann RG, Panepinto JA. A comparison of pain assessment measures in pediatric sickle cell disease: visual analog scale versus numeric rating scale. J Pediatr Hematol Oncol. 2015; $37: 190-194$

13. Mason KP, Michna E, Zurakowski D, Burrows PE, Pirich MA, Carrier M, Fontaine PJ, Sethna NF. Value of bispectral index monitor in differentiating between moderate and deep Ramsay Sedation Scores in children. Pediatr Anesth. 2006; 16:1226-1231.

14. Ma Z, Wang X, Dong M, Huang S. Early effect of tonsillotomy on children's snoring with tonsil hypertrophy. Int J Lab Med. 2016; 37:484-486.

15. Tang A, Gropler M, Duggins AL, Amin RS, Shott SR, Chini B, Ishman SL. Gaps in evidence: management of pediatric obstructive sleep apnea without tonsillar hypertrophy. Laryngoscope. 2016; 126:758-762.

16. Chen L, Zhang R, Zhu S, Hua C. The influence of remifentanil combined with propofol or sevoflurane on children undergoing tonsillectomy or adenoidectomy for postoperative agitation. China Mod Dr. 2016; 54:81-83.

17. Bochner RE, Gangar M, Belamarich PF. A clinical approach to tonsillitis, tonsillar hypertrophy, and peritonsillar and retropharyngeal abscesses. Pediatr Rev. 2017; 38:81-92.

18. Yi Y, Zhao M, Xu F, Liu C, Yin Y, Yu J. CGRP 4218T/C polymorphism correlated with postoperative analgesic effect of fentanyl. Int J Clin Exp Pathol. 2015; 8:5761-5767.

19. Lee SH, Kim JD, Park SA, Oh CS, Kim SH. Effects of $\mu$-opioid receptor gene polymorphism on postoperative nausea and vomiting in patients undergoing general anesthesia with remifentanil: double blinded randomized trial. J Korean Med Sci. 2015; 30:651-657.

20. Alsuliman A, Muftuoglu M, Khoder A, Ahn YO, Basar R, Verneris MR, Muranski P, Barrett AJ, Liu E, Li L, Stringaris $\mathrm{K}$, Armstrong-James D, Shaim H, et al. A subset of virusspecific CD161(+) T cells selectively express the multidrug transporter MDR1 and are resistant to chemotherapy in AML. Blood. 2017; 129:740-758.

21. Hagihira S, Takashina M, Mori T, Mashimo T. Can 1\% sevoflurane with $5 \mathrm{ng} / \mathrm{ml}$ remifentanil prevent implicit memory. Anesthesiology. 2007; 107(6):1030; author reply 1031.

22. Huang H, Peng C, Liu Y, Liu X, Chen Q, Huang Z. Genetic association of NOS1 exon18, NOS1 exon29, ABCB1 $1236 \mathrm{C} / \mathrm{T}$, and $\mathrm{ABCB} 13435 \mathrm{C} / \mathrm{T}$ polymorphisms with the risk of Parkinson's disease: a meta-analysis. Medicine. 2016; 95:e4982.
23. Verkoyen K, Schildhauer TA, Strauch JT, Swol J. The effects of propofol and isoflurane sedation on the outcomes of surgical patients receiving extracorporeal membrane oxygenation. ASAIO J. 2017; 63:174-178.

24. Choi EK, Seo Y, Lim DG, Park S. Postoperative nausea and vomiting after thyroidectomy: a comparison between dexmedetomidine and remifentanil as part of balanced anesthesia. Korean J Anesthesiol. 2017; 70:299-304.

25. Zhao X, Jin YW, Li HB, Wang ZG, Feng H, Feng C. Effects of maintaining intravenous infusion of remifentanil or propofol on anesthesia and palinesthesia during anesthesia and analepsia. Genet Mol Res. 2014; 13:2865-2872.

26. Hosseinzadeh H, Golzari SE, Torabi E, Dehdilani M. Hemodynamic changes following anesthesia induction and LMA insertion with propofol, etomidate, and propofol+etomidate. J Cardiovasc Thorac Res. 2013; 5:109-112.

27. Zheng M, Guo Y, Shan S, Yang S. Dezocine for anesthesia and stress reduction in induced abortion. Patient Prefer Adherence. 2015; 9:369-372.

28. Olanipekun SO, Adekola OO, Desalu I, Kushimo OT. The effect of pre-incision field block versus post-incision inguinal wound infiltration on postoperative pain after paediatric herniotomy. Open Access Maced J Med Sci. 2015; 3:666-671.

29. Choi EM, Lee MG, Lee SH, Choi KW, Choi SH. Association of ABCB1 polymorphisms with the efficacy of ondansetron for postoperative nausea and vomiting. Anaesthesia. 2010; 65:996-1000.

30. Kesimci E, Engin AB, Kanbak O, Karahalil B. Association between ABCB1, gene polymorphisms and fentanyl's adverse effects in Turkish patients undergoing spinal anesthesia. Gene. 2012; 493:273-277.

31. Sadhasivam S, Chidambaran V, Zhang X, Meller J, Esslinger H, Zhang K, Martin LJ, McAuliffe J. Opioidinduced respiratory depression: $\mathrm{ABCB} 1$ transporter pharmacogenetics. Pharmacogenomics J. 2015; 15:119-126.

32. Sia AT, Sng BL, Lim EC, Law H, Tan EC. The influence of ATP-binding cassette sub-family B member -1 (ABCB1) genetic polymorphisms on acute and chronic pain after intrathecal morphine for caesarean section: a prospective cohort study. Int J Obstet Anesth. 2010; 19:254-260.

33. Farhat K, Iqbal J, Waheed A, Mansoor Q, Ismail M, Pasha AK. Association of anti-emetic efficacy of ondansetron with G2677T polymorphism in a drug transporter gene ABCB1 in Pakistani population. J Coll Physicians Surg Pak. 2015; $25: 486-490$. 